DEPUR: A Knowledge-Based Tool

for Wastewater Treatment Plants

Pau Serra

Miquel Sánchez

Javier Lafuente

Ulises Cortés

Manel Poch

Report LSI-93-39--R

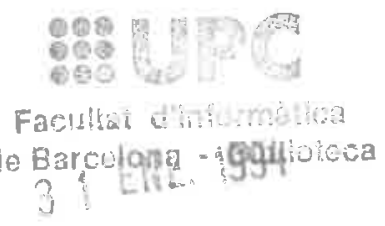




\title{
DEPUR: a knowledge-based tool for wastewater treatment plants*
}

\author{
${ }^{1}$ Pau Serra, ${ }^{2}$ Miquel Sànchez, ${ }^{1}$ Javier Lafuente, ${ }^{2}$ Ulises Cortés, ${ }^{1}$ Manel Poch \\ ${ }^{1}$ Universitat Autònoma de Barcelona \\ Unitat d'Enginyeria Bioquímica (CSIC - UAB) \\ Edifici C. E-08193 Bellaterra (Barcelona). Catalonia. \\ iqte2@cc.uab.es \\ ${ }^{2}$ Universitat Politècnica de Catalunya \\ Departament de Llenguatges i Sistemes Informàtics (IA) \\ C/ Pau Gargallo 5. E-08028 Barcelona. Catalonia. \\ sanchez@lsi.upc.es, ia@lsi.upc.es
}

\begin{abstract}
A malfunction of a wastewater treatment plant is a big social and biological problem. A poorly treated waste water outside the plant could provoke dangerous consequences for human beings as well as the nature itself. The conventional control systems, that are usually applied in this field, have to cope with some difficulties: complexity of the system, an ill-structured domain, qualitative information, uncertainty or approximate knowledge, real-time dynamic system, ... This paper shows an application of artificial intelligence in order to help the operators of wastewater treatment plants in their task of process control. The main goal is to build a knowledge-based tool useful for the diagnosis and management of wastewater treatment plants. First, is made a survey on wastewater treatment plants to describe the complexity of the system being modelled and to outline its own difficulties. It is discussed the development of the application and the methodology employed in it. A new methodology called LINNEO ${ }^{+}$is introduced. It is used for the automatic knowledge acquisition process in order to build up a Knowledge Base. The prototype's architecture constructed -DEPUR- is detailed together with some obtained results.
\end{abstract}

Keywords: Knowledge-based Systems, Process Diagnosis and Management, Wastewater treatment, Knowledge Acquisition tools, Environmental Engineering, Biotechnology.

\section{Introduction}

The aim of this work relies on the application of new techniques in the fields of automation and process control. The AI tools, as seen below, are very important aids in the automation of process management. A malfunction of a wastewater treatment plant is a big social and biological problem. A poorly treated waste water outside the plant could provoke dangerous consequences for human beings as well as the nature itself.

*Accepted to be published (2/11/93) in International Journal of Engineering Applications of Artificial Intelligence. Pergamon Press. 
The setting of an automatic process control over the wastewater treatment plant system, has outlined some difficulties:

- The complexity of the problem. There are many facts from different nature present at the system: chemical facts, mechanical, biological, microbiological ones, ...

-A non-well structured domain. The relationships among the concepts or attributes of the domain are not enough known or the agreement among experts is not very high.

- Most information is neither numeric nor quantified. So, it is not suitable to be included in the context of a classical -numerical- control model (microbiological information,...).

- Uncertainty or approximate knowledge. By example, the subjective information supplied by the experience of the plants' managers.

- A dynamic system. Continuous changes that modify directly the performance of the process.

Moreover, it can be said that the classical methods work fine on the normal states of the plant but not in other abnormal states of working. How could they detect some mechanical faults?. How could they use the available information but incomplete one, to solve a specific problem?. These troubles with the conventional process control systems as feed-back control, feed-forward control, optimal control, adaptive control, ... have arisen during last years much research effort in Artificial Intelligence [1-4].

Bringing to mind the main advantages and characteristics of knowledge-based systems, specially those of expert systems, and the above difficulties one could think that match very well. So it has been developed a prototype of a qualitative expert system with uncertainty reasoning and a real time numerical control expert system by the other hand, which is described in [5], for the diagnosis and management of wastewater treatment plants.

\section{A wastewater treatment plant}

The main goal of a wastewater treatment plant is to reduce the level of pollution of the wastewater at the lowest cost, that is, to remove -within possible measure- strange compounds (pollutants) of the inflow water to the plant prior to discharge to the environment. So, the effluent water has low levels of the pollutants (lower than maximum ones allowed by the law). The plants taken as models are based on the main biological technology usually applied: the activated sludge process [6]. The concrete wastewater plant studied is located in Manresa, near Barcelona (Catalonia). This plant receives about 35000 $\mathrm{m}^{3} /$ day inflow from 75000 inhabitants.

A wastewater treatment plant is composed usually by two stand-alone but interactive subsystems: sludge line and water line. The study has focused on the water line. It is formed by a sequence of unitary processes where the effluent of one process becomes the inflow to the next one. Usually there are 3 major processes: primary treatment, secondary treatment and tertiary treatment. Each one reduces or removes the concentration of several specific pollutants. The chart of a plant may be seen in figure 1 . 


\section{Development of the qualitative expert system}

It has been built up an expert system, called DEPUR [7-8], in order to support the approximate or uncertain reasoning, qualitative knowledge, ... in the managing of wastewater treatment plants. The main problem appearing on a wastewater treatment plant is the breakdown of the balance between biomass and substrate, as shown in figure 2 . The biomass is formed by a set of microbiological beings that in presence of oxygen, degrade non-sedimentable organic suspended solids (i. e., the substrate) in the water. More information about the wastewater treatment processes can be found in classical bibliography [9-10].Thus, the task of diagnosis of the system tries to determine the causes of the problems detected. Often, the most serious problems are related to the biological process in the secondary treatment.

\section{Figure 2 here}

The design process of a knowledge-based system can be expressed commonly as shown in figure 3. The work has been focused on the water line subsystem domain. The relevant attribute selection process has been developed twofold: firstly, in a typical manner based on the attribute selection made by the experts of the domain, and, secondly, by means of a new automatic attribute selection approach based on the relevance and potential utility concepts [11].

Figure 3 here

The attribute structuring process has been made over two approaches:

- Decision trees: the classical approach derived from the interactions between the expert and the engineer. This approach is governed by the cause-effect criterion. Multi-valued decision trees have been used and inference rules are obtained from them. The rules point out to discover the causes of a certain problem or situation previously detected.

- Automatic classification techniques: used as an automatic knowledge acquisition tool is an approach recently derived from machine learning in Artificial Intelligence.

The LINNEO $^{+}$system, based on fuzzy non-well structured domain classifications, has been used in this phase. From the characterization of the obtained classes, more general inference rules are constructed. They lead to know the most likely working situation of the plant. This methodology will be explained more accurately in next section.

Decision trees have been used in the causes identification phase and automatic classification techniques in the problem identification process as shown in figure 4 . 
- Objects -situations- defined:

- Normal

- Bulking-non-filamentous
- High plant inflow

- Rotation-band-crash

- Bulking-not-emough-oxygen

- Bulking-sulphurs

- Primary-sludge-sedim.-problem

- Rising

- Not-enough-primary-sludge-exit

- Foaming

- Overaeration

- Summer

- Winter

- Storm

- Overloading

- Turbine-crash

- By-pass-bad-closed

- Toxic-substances-loading

- Toxic-substances-increase

- Attributes defined:

- Rotate-band-clarifiers

- Sulphurs

- Bubbles-clarifiers

- Bubbles-primary-settlers

- Sludge-exit-primary-settler

- Inflow-water

- Suspended Solids-bassins

- Suspended Solids-inflow

- Dissolved-Oxygen

- Inflow-DQO

- Suspended Solids-outflow

- Outflow-DQO

- Volatile Suspended Solids-bassins

- Sludge-age

- Volatile Suspended Solids-recirculat.

- Foam-bassins

- Temperature

- Turbines

- Filamentous

- Toxic-substances-bassins

- SVI

- Toxic-substances-inflow

An example of a complete observation with its values for the attributes may be like this one:

-Bulking-non-filamentous:

$\begin{array}{lll}\text { Outflow-DQO } & \longrightarrow & \text { High } \\ \text { Sludge age } & \longrightarrow & \text { Old } \\ \text { Filamentous } & \longrightarrow & \text { Normal } \\ \text { SVI } & \longrightarrow & \text { High } \\ \text { Volatile SS-recirculation } & \longrightarrow & \text { Low } \\ \text { All-other-attributes } & \longrightarrow & \text { Nought-value }\end{array}$

The other attributes have nought values [14] or don't care values. It means that the values of these attributes are not relevant for the characterization of the object. Although they could be relevant to describe other working situations of the plant. For instance, in the above example, the value of the attribute temperature could be anyone -but don't care which is-for the description of the bulking situation originated by non-filamentous causes. 


\subsection{Results}

10 classes have been obtained (see figure 6) as a result of the classification process. Each one, groups closely related prototypical situations. The classification shows the most common situations and problems in the working state of the wastewater treatment plant and makes easier the arrangement of the underlying domain. These classes lead the inference process in the diagnosis.

\section{Figure 6 here}

\section{Implementation of DEPUR in MILORD}

MILORD [15-16] is a classical second generation expert system shell, but considerations have been made on some important features related to this particular domain, as the microbiological and temporal ones. The application developed is called DEPUR and reflects the experts knowledge. See figure 7. The Data Base is a representation of the current state of the system, that could include some past or future facts of interest. In this representation are selected the attributes more relevant for the domain characterization. The dictionary of the Data Base is composed by 167 attributes with a decrease by means of relevant and potential utility concepts. An example of dictionary entries may be:

\section{(INFLOW-WATER-NORMAL}

"Has the inflow water normal values $(35000-45000) \mathrm{m}^{3} /$ day ?"

FUZZY)

\section{(LOW-TEMPERATURE}

"Is the temperature low $(<5)^{\circ} \mathrm{C}$ ?"

FUZZY)

The Knowledge Base is the arrangement of the knowledge you have over the domain, made explicit by the expert and by information coming from the analysis of the system being modelled. Usually, this knowledge is expressed by means of inference rules. Examples of rules may be:

\section{(RMENU003B}

(IF (DQO-EFLUENT-WATER-HIGH SLUDGE-AGE-YOUNG))

SURE

(THEN

(INFER (CLASS-3B))))

(RC3004

(IF (CLASS-3A

DISSOLVED-OXYGEN-LOW

ODOR-BASSINS))

SURE

(THEN

(INFER (BULKING-O2)))) 
The system is formed by 79 rules, grouped in 12 modules. A module is a structural element of the Knowledge Base, composed by a set of related rules.

\section{Figure 7 here}

The Control Module has the goal of control how and when may be used the knowledge supported by the system. Often it is expressed by means of metarules. The prototype has got 15 metarules. An example of a metarule may be:

(M003B

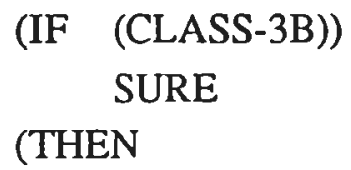

(TREAT-MODULES C3)))

The linguistic terms used to manage the approximate knowledge are in order of certainty:
Sure
Almost-sure
Very-possible
Possible
Moderately-possible
Slightly-possible
Almost-impossible
Impossible

The modularity of the application, the self-explanation and the user friendly interface afforded by the shell are other outstanding properties.

\section{Validation}

The prototype diagnostics in contrast to the answers of human experts, has yielded very good results. It has been tested with several prototypical situations in the working of the plant (bulking, foaming, ...).

Currently, this classification is validated against a data stream daily obtained from direct observation in the wastewater treatment plant during the last 2 years, with very high degree of performance.

A short dialogue with the application could be like the following one:

$>$ Has the effluent $D B O$ high values $(25-40) \mathrm{mg} / \mathrm{l}$ ?

- Sure

$>$ Has the water inflow high values $(45000-55000) \mathrm{m}^{3} /$ day?

- Almost impossible

$>$ Is the temperature low $(<5)^{\circ} \mathrm{C}$ ?

- Impossible 
$>$ Has the inflow water high concentration of $\mathrm{Zn}(4-20) \mathrm{mg} /$ ?

- Impossible

$>$ Is the Volumetric index of sludge (SVI) high (150 - 300) $\mathrm{mg} /$ ?

- Very possible

$>$ Are the Suspended Solids (SS) in the recirculation low (1300-4600) $\mathrm{mg} /$ ?

- Sure

$>$ Are the Volatile Suspended Solids (SSV) in the recirculation low (1000-3500) $m g /$ ?

- Sure

$>$ Has the dissolved oxygen (DO) high values $(2.5-10) \mathrm{mg} /$ ?

- Impossible

$>$ Is the age of sludge old (8-20) days?

- Impossible

$>$ Conclusion $\rightarrow \mathbb{B}$ ulking-not-enough-oxygen-Very-possible

\section{Conclusions and future work}

The building of DEPUR system as a prototype of fuzzy expert system applied to managing a wastewater treatment plant, has been the consequence of the research effort during last years (study and modelling of wastewater treatment plants, development of new techniques of selection and arrangement of attributes, building of computer systems, ...) by both scientific groups involved.

A diagnosis and managing tool based on knowledge-based systems for a wastewater treatment plant may be a useful approach in the field of intelligent systems applied to managing industrial processes.

The prototype may be helpful for the manager of the plant. The treatment of uncertainty and the new fuzzy techniques for automatic classification are some of its characteristics. This methodology has been successfully applied to other domains. See [11-12].

This project supposes a step towards the building of intelligent systems oriented to preserve the water, as part of the nature (ecological intelligent systems).

Other interesting point is the possibility to adapt the system to the specific characteristics of the concrete wastewater treatment plant under control.

In the future, it is proposed to reach a second step: the development of a Supervisor Knowledge-Based System -more powerful than an expert system-, that join diagnosis and control including the numerical control algorithms [17] with qualitative and heuristic information and reasoning. See figure 8.

Also there is much work to do: extend the domain to the sludge line, research in a more accurate way the microbiological compound of the biological process and make a better temporal information treatment.

Figure 8 here 


\section{Acknowledgements}

This work has been supported by the "Junta de Sanejament de la Generalitat de Catalunya" and the Spanish CICyT projects ROB89-0479-C03-02, ROB91-1139 and TIC91-1087C03-01. Also the authors wish to acknowledge the cooperation of Ricard Tomàs, manager of the Manresa's wastewater treatment plant.

\section{References}

1. J.J. Coleman, S. Krovvidy, R. Scott Summers, W.G. Wee. "An AI Approach for Wastewater treatment systems". Journal of Applied Intelligence vol. I, num. 3, pp. 247-261. Kluwer Academic Publishers (1991).

2. V. Floris. "Artificial Intelligence in the operation and management of water resources in South Florida". Personal Communication (1989).

3. K. Maeda. "A knowledge-based system for the wastewater treatment plant". Future Generation Computer Systems 5, pp. 29-32. North Holland (1989).

4. R. Sanz, J, Aguilar, C. Sierra, Ll. God6, A. Ollero. "Adaptive control with a supervisor level using a rule-based inference system with approximate reasoning". Artificial Intelligence in Scientific Computation: towards 2nd generation systems. IMACS (1989).

5. P. Serra , M. Sànchez, J. Lafuente, U. Cortés, M. Poch. "ISCWAP: a knowledge based system for supervising activated sludge processes". Submitted (1993).

6. J. Robusté. "Modelització i identificació del procés de fangs activats". Ph. D. Thesis. Departament de Química. Universitat Autònoma de Barcelona (1990).

7. M. Sànchez, P. Serra, Ll. Belanche, U. Cortés. "A knowledge-based system for the diagnosis of waste-water treatment plants". Proc. of 5th International Conference on Industrial \& Engineering Applications of Artificial Intelligence and Expert Systems (IEA/AIE-92). Springer-Verlag. Lecture Notes in Artificial Intelligence 604, pp. 324-336. Paderborn, Germany. (1992).

8. M. Sànchez. "DEPUR: Aplicació dels sistemes basats en el coneixement al diagnòstic en plantes de tractament d'aiguies residuals". Master Thesis. Departament de Llenguatges i Sistemes Informàtics. Universitat Politècnica de Catalunya (1991).

9. L.D. Benefield, C.W. Randall. Biological process design for wastewater treatment. Prentice-Hall. N.J. (1980).

10. Metcalf \& Eddy Inc. Wastewater engineering: treatment/disposal/reuse. Mc Graw-Hill, 3th edition (1991).

11. Ll. Belanche, U. Cortés. "The nought attributes in knowledge-based systems". Proc. of the European workshop on Verification \& Validation, EUROVAV-91, pp. 77-103. Jesus College. Cambridge. UK. (1991). 
12. J. Béjar, U. Cortés. "LINNEO+: Herramienta para la adquisición de conocimiento y generación de reglas de clasificación en dominios poco estructurados". Actas 3er Congreso Iberoamericano de Inteligencia Artificial, IBERAMIA-92, pp. 471-481. La Habana, Cuba (1992).

13. M. Martín, R. Sangüesa, U. Cortés. "Biasing induction with previous knowledge for knowledge acquisition in imprecise domains". Proc. Avignon '91, pp. 359-370. 1991.

14. E. Sánchez. "Importance in knowledge systems". Information System 14 (6), pp. 455464 (1989).

15. L. God6, R. López de Mántaras, C. Sierra, A. Verdaguer. "MILORD: the architecture and management of linguistically expressed uncertainty". Int. Journal of Intelligent Systems 4, pp. 471-501 (1989).

16. C. Sierra. "MILORD: arquitectura multi-nivell per a sistemes experts en classificació". PH. D. Thesis. Departament de Llenguatges i Sistemes Informàtics. Universitat Politècnica de Catalunya (1989).

17. R. Moreno, C. de Prada, J. Lafuente , M. Poch, G. Montague. "Non-linear predictive control of dissolved oxygen in the activated sludge process". In Modelling and Control of biotechnological processes, pp. 289-293. Ed. M.N. Karim, G. Stephanopoulos (1992). 
Fig. 1 - Chart of a wastewater treatment plant Fig. 2 - Biological balance

Fig. 3 - Design process of a Knowledge-Based System Fig. 4 - Diagnostic process in an Expert System Fig. 5 - The methodology of LINNEO+ Fig. 6 - Results of the classification process Fig. 7 - General architecture of DEPUR Fig. 8 - A Supervisor Knowledge-Based System 


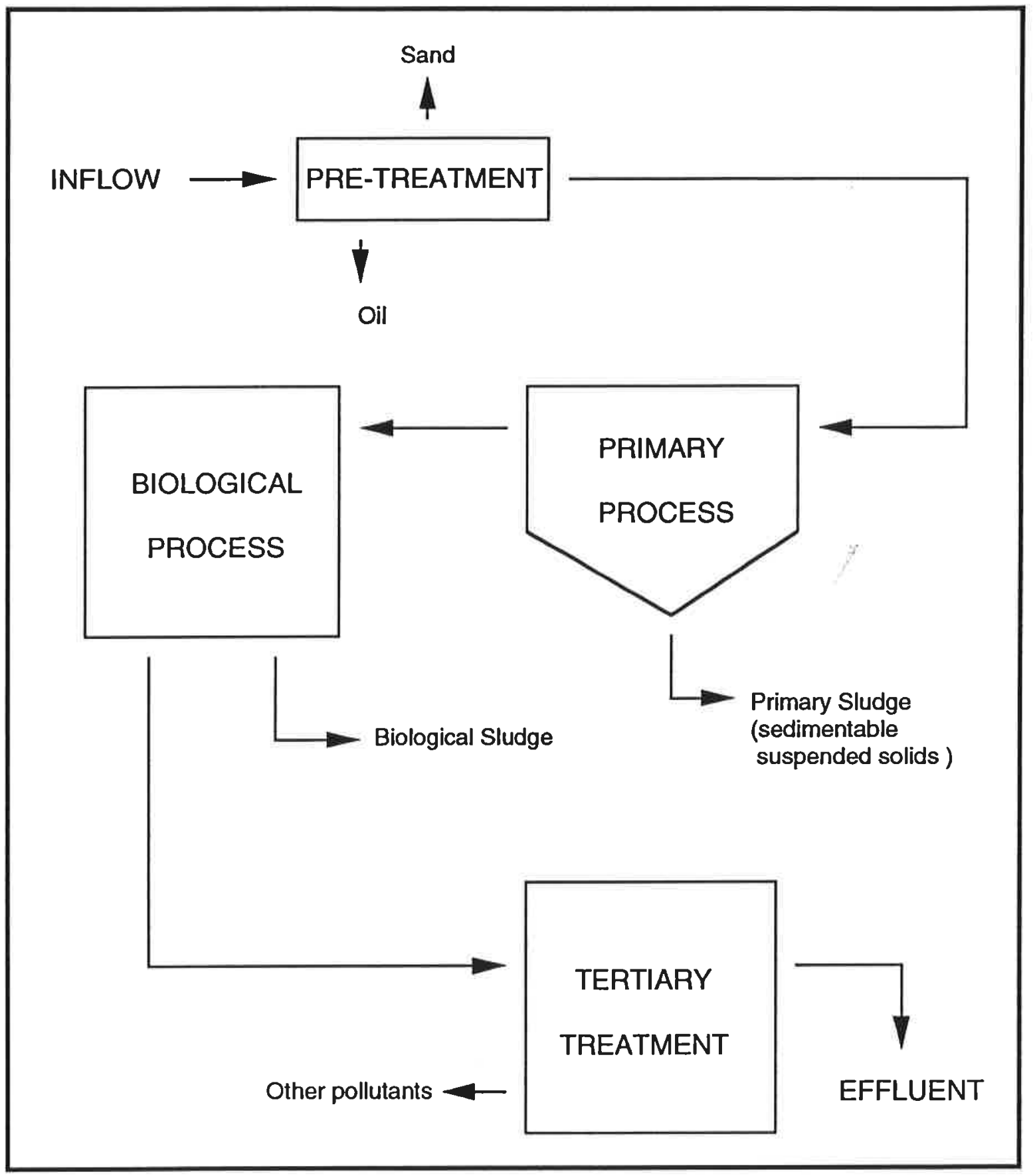




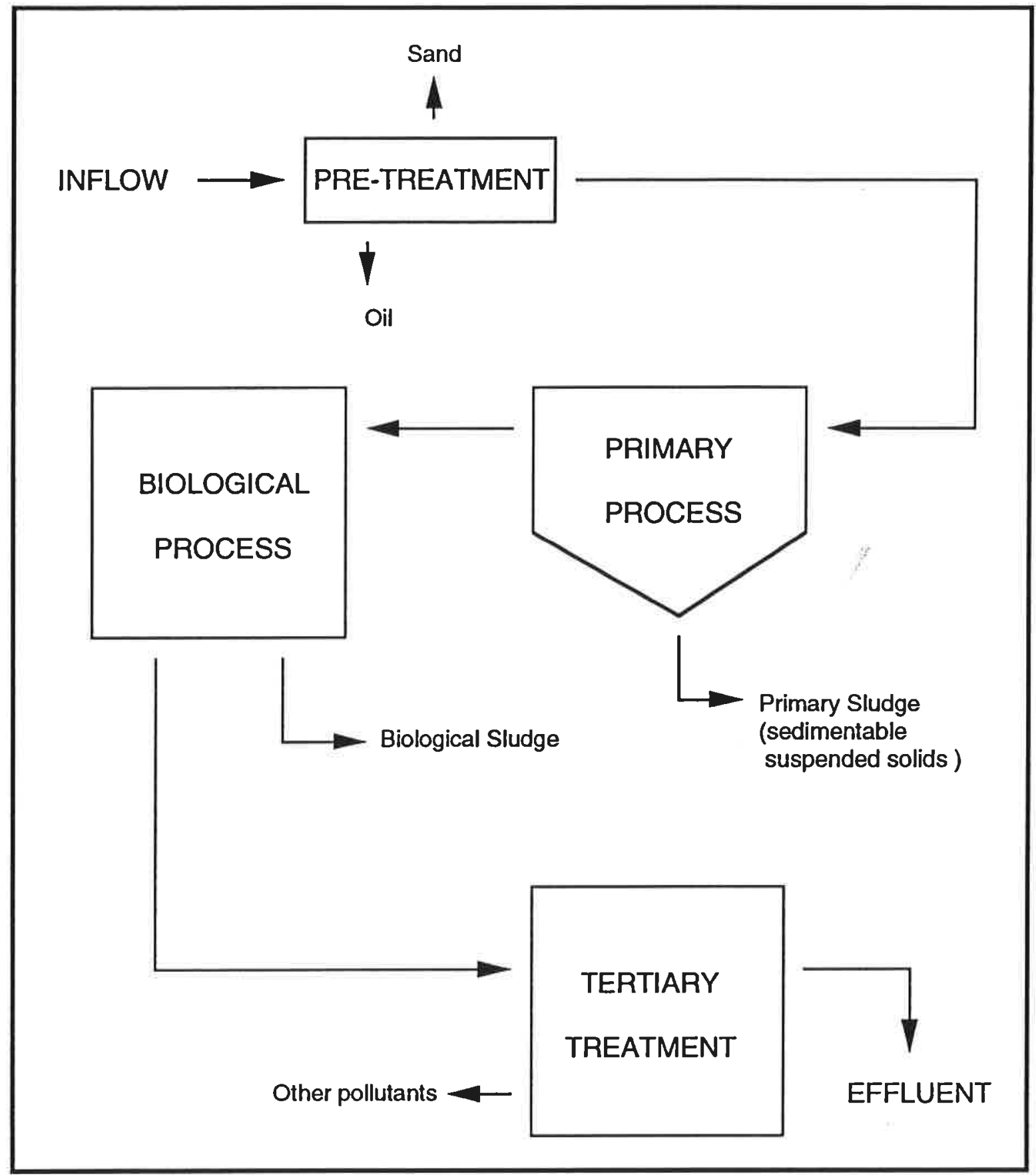




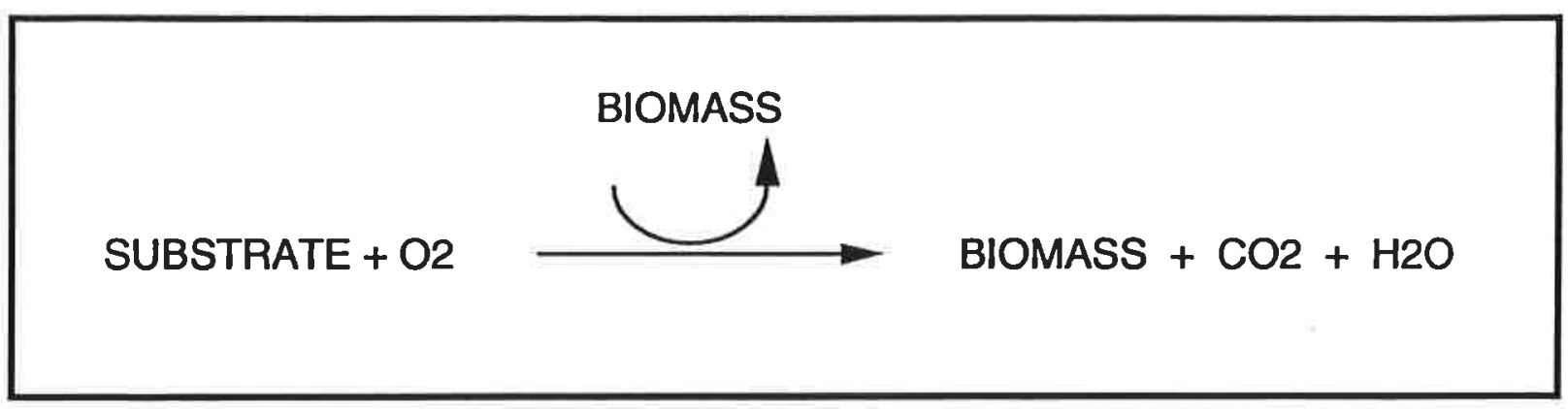




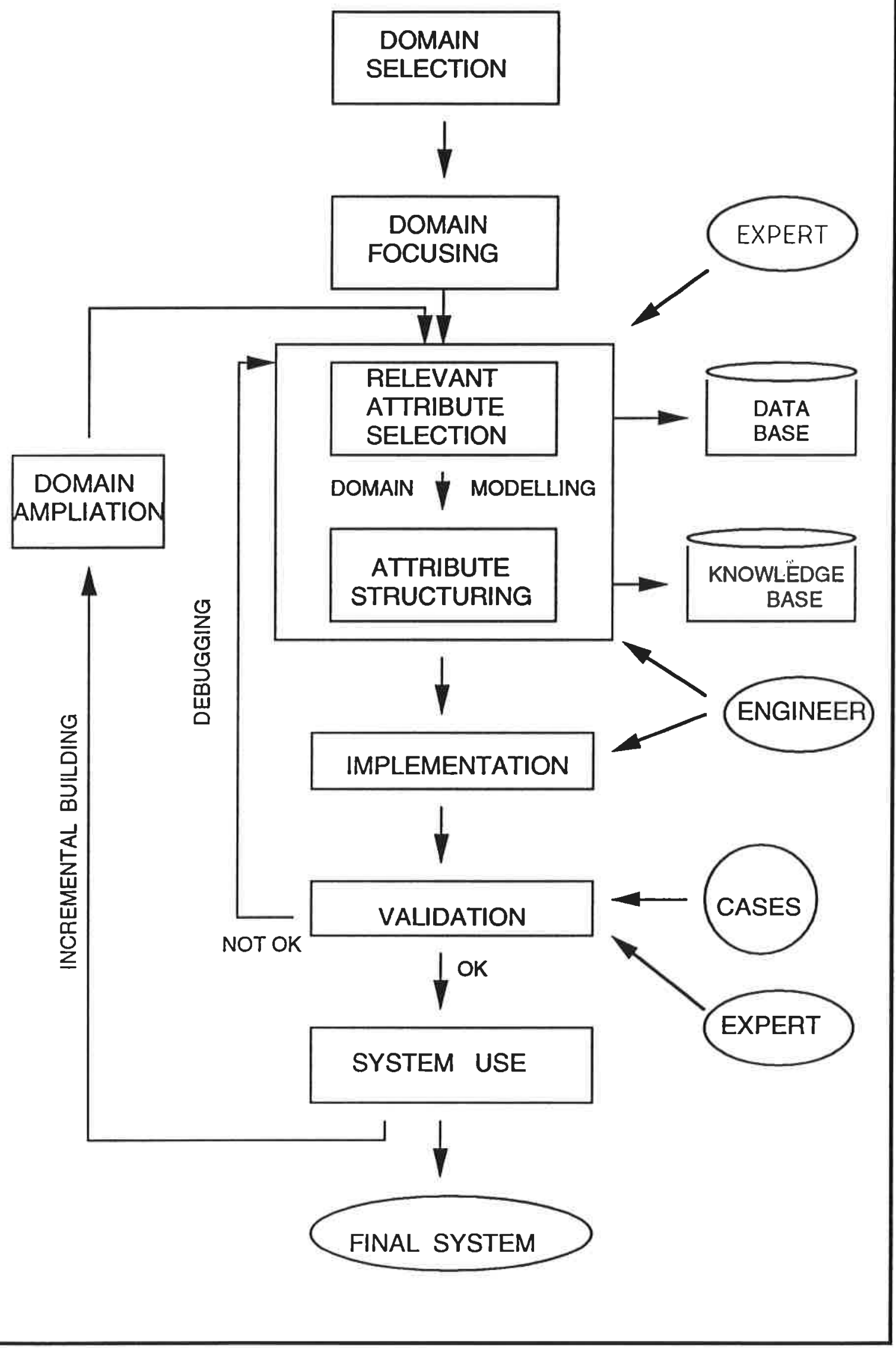




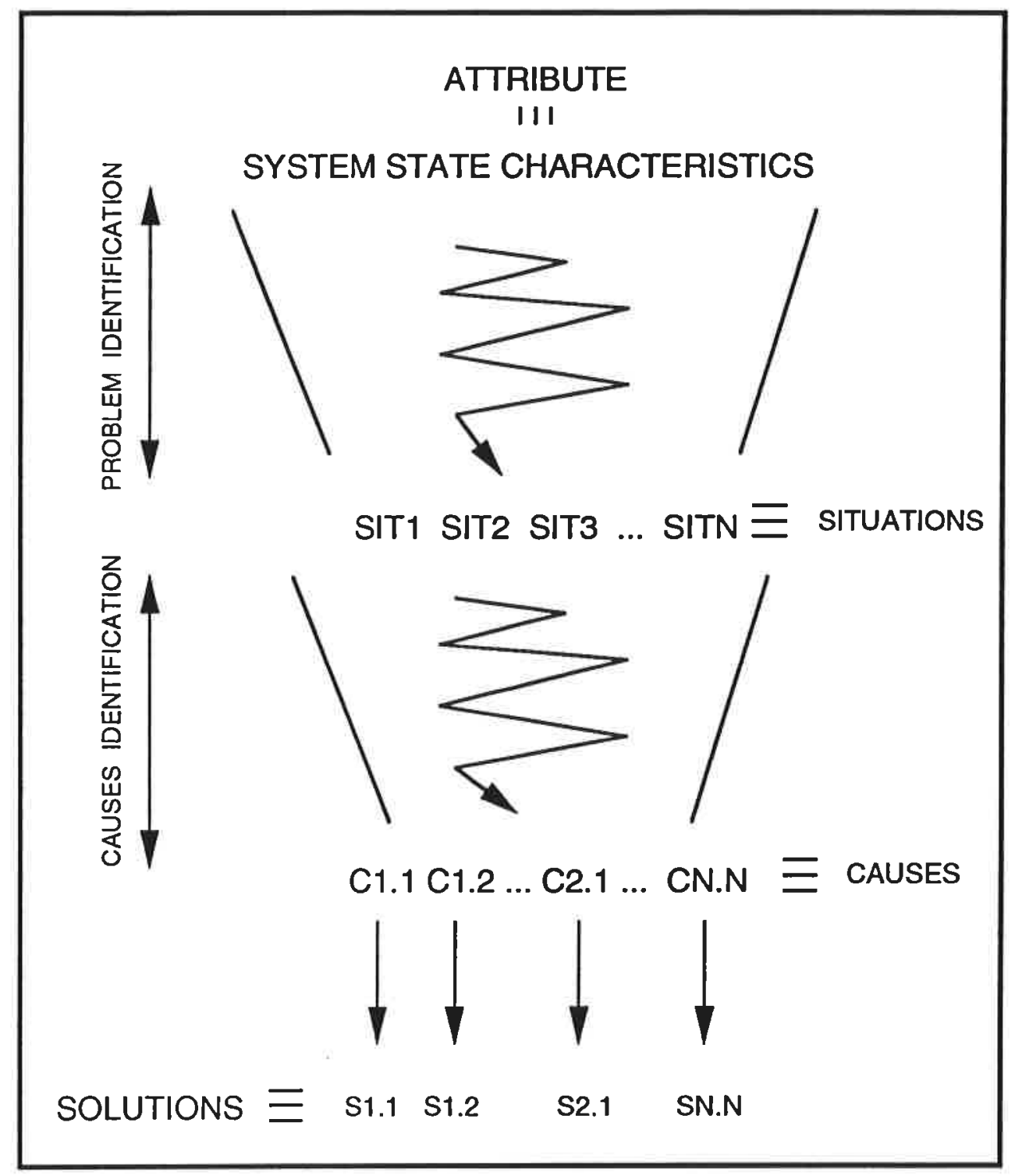




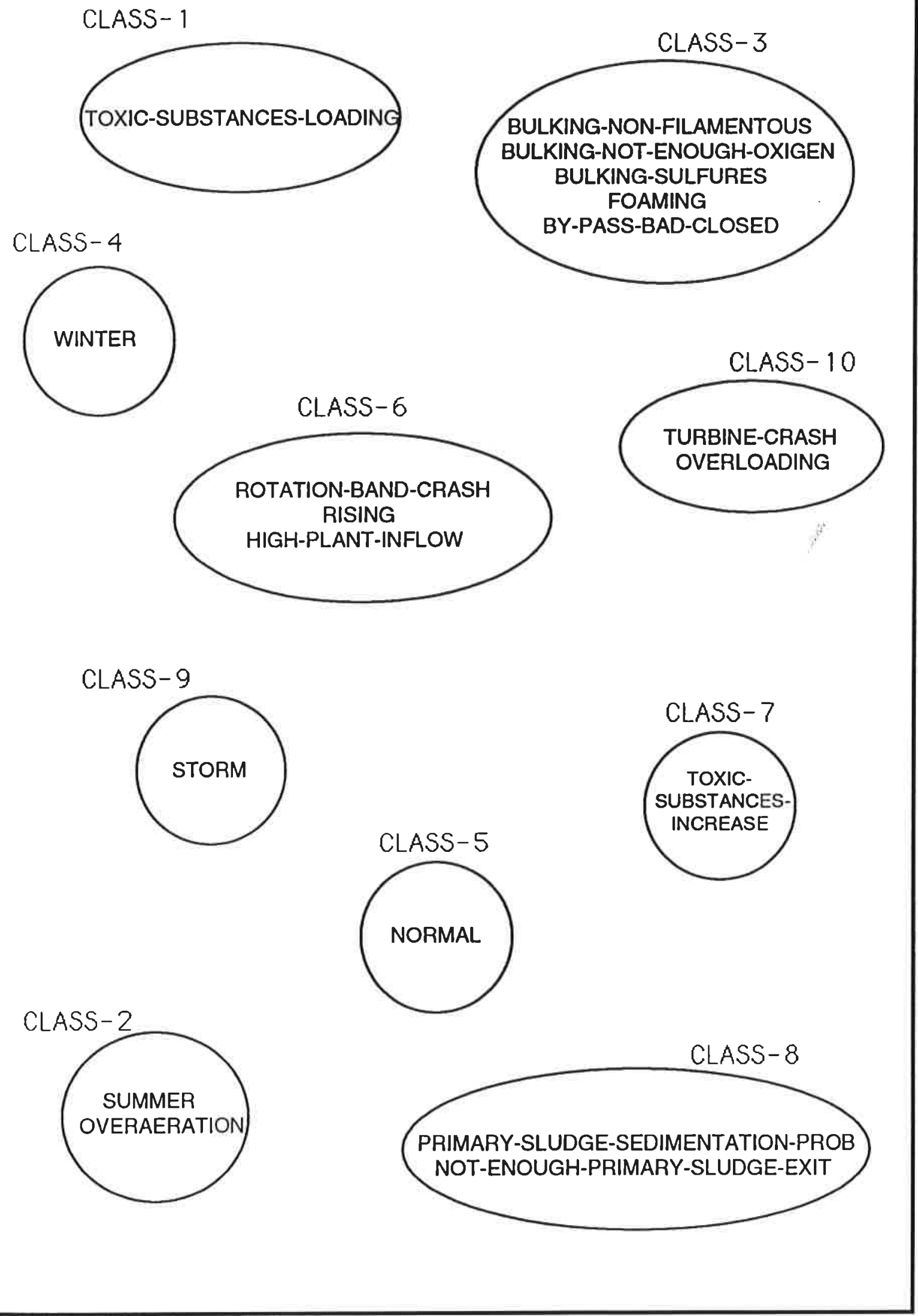




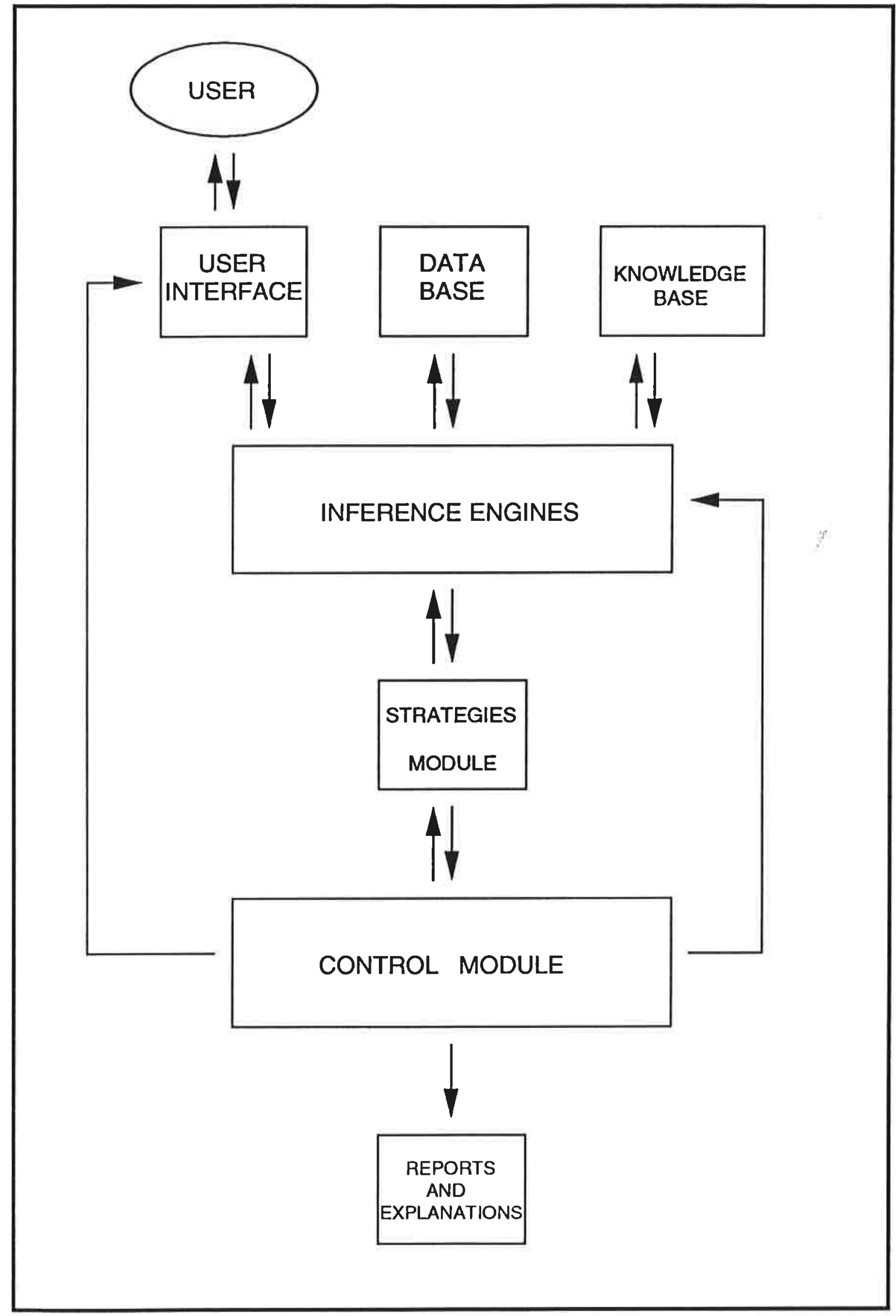




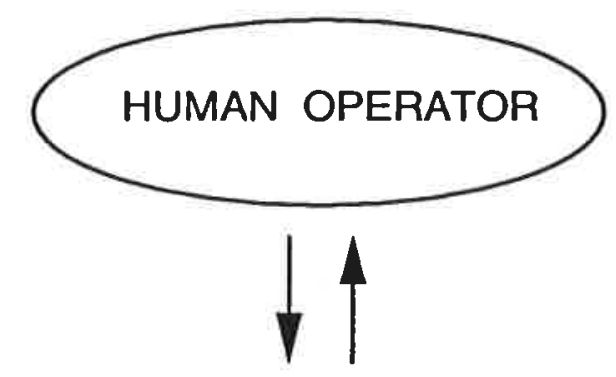

KNOWLEDGE BASED SUPERVISOR SYSTEM

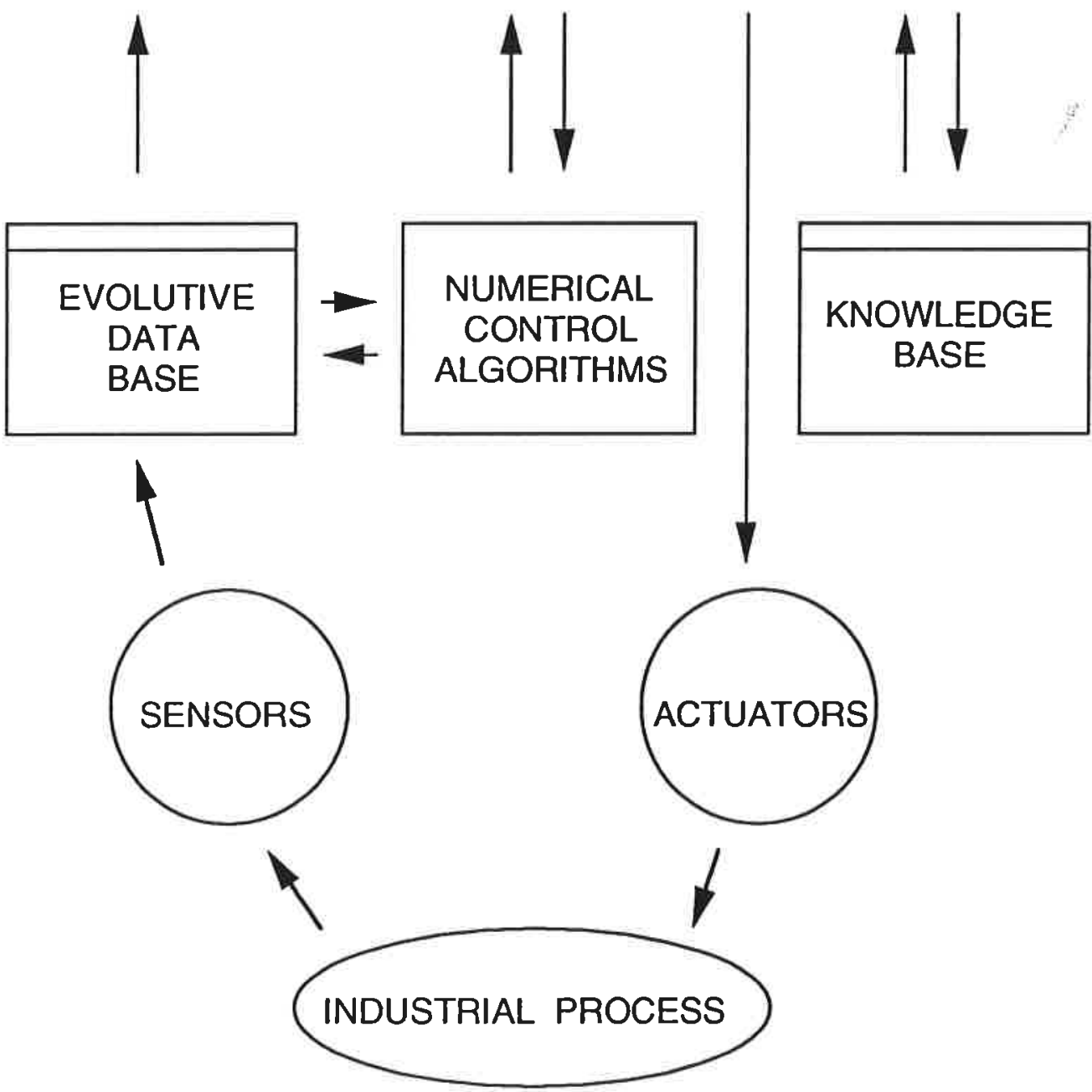




\section{Departament de Llenguatges i Sistemes Informàtics Universitat Politècnica de Catalunya \\ List of research reports (1993).}

LSI-93-1-R “A methodology for semantically enriching interoperable databases", Malú Castellanos.

LSI-93-2-R "Extraction of data dependencies", Malú Castellanos and Fèlix Saltor.

LSI-93-3-R "The use of visibility coherence for radiosity computation", X. Pueyo.

LSI-93-4-R “An integral geometry based method for fast form-factor computation", Mateu Sbert.

LSI-93-5-R "Temporal coherence in progressive radiosity", D. Tost and X. Pueyo.

LSI-93-6-R "Multilevel use of coherence for complex radiosity environments", Josep Vilaplana and Xavier Puejo.

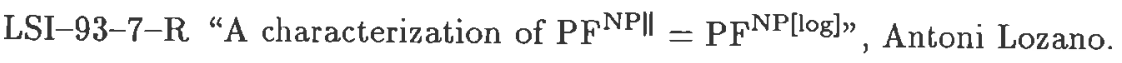

LSI-93-8-R "Computing functions with parallel queries to NP", Birgit Jenner and Jacobo Torán.

LSI-93-9-R “Simple LPO-constraint solving methods", Robert Nieuwenhuis.

LSI-93-10-R "Parallel approximation schemes for problems on planar graphs", Josep Díaz, María J. Serna, and Jacobo Torán.

LSI-93-11-R "Parallel update and search in skip lists", Joaquim Gabarró, Conrado Martínez, and Xavier Messeguer.

LSI-93-12-R "On the power of Equivalence queries", Ricard Gavaldà.

LSI-93-13-R "On the learnability of output-DFA: a proof and an implementation", Carlos Domingo and David Guijarro.

LSI-93-14-R "A heuristic search approach to reduction of connections for multiple-bus organization", Patricia Ávila.

LSI-93-15-R “Toward a distributed network of intelligent substation alarm processors", Patricia Ávila.

LSI-93-16-R "The Odissea approach to the design of information systems from deductive conceptual models", Maria Ribera Sancho and Antoni Olivé.

LSI-93-17-R "Constructing face octrees from voxel-based volume representations", Robert Juan i Ariño and Jaume Solé i Bosquet. 
LSI-93-18-R "Discontinuity and pied-piping in categorial grammar", Glyn Morrill.

LSI-93-19-R "El frau i la delinqüència informàtica: un problema jurídic i ètic", Miquel Barceló (written in Catalan).

LSI-93-20-R "Non-homogeneous solid modeling with octrees. A geological application", Anna Puig, Isabel Navazo, and Pere Brunet.

LSI-93-21-R "Extending a single resolution system towards a distributed society", Karmelo Urzelai.

LSI-93-22-R "LINNEO+: A classification methodology for ill-structured domains", Javier Béjar, Ulises Cortés, and Manel Poch.

LSI-93-23-R "Especificació d'una biblioteca de tipus" (written in Catalan), Xavier Franch.

LSI-93-24-R "Proceedings of the Fourth Barcelona-Ulm Workshop on Probabilistic Complexity Classes and Nonuniform Computational Models" (Barcelona, September 13th-17th, 1993), José L. Balcázar and Antoni Lozano (editors).

LSI-93-25-R "Proceedings of the Fourth International Workshop on the Deductive Approach to Information Systems and Databases" (Lloret de Mar, 1993), Antoni Olivé (editor).

LSI-93-26-R "Modelo para el control de calidad en LESD basado en la medición del software" (written in Spanish), O. Slávkova.

LSI-93-27-R "On the robustness of ALMOST-R", Ronald V. Book and Elvira Mayordomo.

LSI-93-28-R "Lexicografía computacional: Adquisición automática de Conocimiento Léxico" (written in Spanish), Irene Castellón Masalles.

LSI-93-29-R "Anàlisi de les definicions verbals del diccionari Vox" (written in Catalan), Mariona Taulé Delor.

LSI-93-30-R "The structure of a logarithmic advice class", Montserrat Hermo.

LSI-93-31-R "Toward a realistic semantics of possible worlds for logics of belief", Gustavo Núñez, Matias Alvarado, and Ton Sales.

LSI-93-32-R "Conocimiento en mundos posibles mediante una relación de posibilidad constructiva" (written in Spanish), Matías Alvarado.

LSI-93-33-R “Not-Yet classification algorithm”, Josep Roure and Javier Béjar.

LSI-93-34-R "Concatenation versus addition in knapsack problems", Birgit Jenner.

LSI-93-35-R "Research Trends in Volume Modeling", Isabel Navazo, Anna Puig, and Dani Tost.

LSI-93-36-R "On Kobayashi's compressibility of infinite sequences", Montserrat Hermo.

LSI-93-37-R "A global algorithm for linear radiosity”, Mateu Sbert and Xavier Pueyo. 
LSI-93-38-R “An optimal parallel algorithm for learning DFA”, José L. Balcázar, Josep Díaz, Ricard Gavaldà, and Osamu Watanabe.

LSI-93-39-R "DEPUR: a knowledge-based tool for wastewater treatment plants", Pau Serra, Miquel Sánchez, Javier Lafuente, Ulises Cortés, and Manel Poch.

Internal reports can be ordered from:

Nuria Sánchez

Departament de Llenguatges i Sistemes Informàtics (U.P.C.)

Pau Gargallo 5

08028 Barcelona, Spain

secrelsiolsi.upc.es 